\title{
Bangkok to Sendai and Beyond: Implications for Disaster Risk Reduction in Asia
}

\author{
Ranit Chatterjee $^{1} \cdot$ Koichi Shiwaku $^{1} \cdot$ Rajarshi Das Gupta $^{1} \cdot$ Genta Nakano $^{1} \cdot$ \\ Rajib Shaw ${ }^{1}$
}

Published online: 16 June 2015

(c) The Author(s) 2015. This article is published with open access at Springerlink.com

\begin{abstract}
The recently concluded World Conference on Disaster Risk Reduction (WCDRR) in Sendai, Japan and the Sendai Framework for Disaster Risk Reduction 2015-2030 (SFDRR) have set renewed priorities for disaster risk reduction (DRR) for the next 15 years. Due to Asia's high exposure to natural hazards, the implications of the new SFDRR have major significance for the future development of the region. The 6th Asian Ministerial Conference on Disaster Risk Reduction (AMCDRR), held in Bangkok in 2014, was a regional preparatory meeting for the WCDRR, and proposed various targets and indicators for DRR in Asia. The AMCDRR recommended inclusion of these goals in the SFDRR. This study focuses on the WCDRR negotiations, particularly outcomes that affect four major groups: local authorities; children and youth; science and technology; and business and industry. An analysis is undertaken of the overlaps and gaps in the outcomes of the 6th AMCDRR and other preceding conferences that fed into the WCDRR. A set of recommendations has evolved from this examination for consideration at the upcoming 7th AMCDRR in 2016. The areas that merit consideration in the upcoming AMCDRR 2016 are: (1) development of baseline data and quantitative indicators for monitoring progress in DRR; (2) creation of a common stakeholder platform; (3) construction of city typologies for consideration in all future local level planning; (4) promotion of a culture of safety by linking large enterprises with small and medium enterprises; and
\end{abstract}

Rajib Shaw

shaw.rajib.5u@kyoto-u.ac.jp

1 Graduate School of Global Environmental Studies, Kyoto University, Yoshida Honmachi, Sakyo-Ku, Kyoto 606-8501, Japan
(5) exchange and sharing of information and databases between regions at all scales.

Keywords Asian Ministerial Conference on Disaster Risk Reduction · Bangkok · Disaster risk reduction - Sendai - World Conference on Disaster Risk Reduction

\section{Introduction}

In the last decade, Asia has experienced 1730 natural disasters that resulted in a loss of approximately USD 752 billion, which is $39 \%$ of all natural disasters in the world and almost $50 \%$ of the total disaster losses (Guha-Sapir et al. 2015). Recent trends suggest an increase in physical and economic exposure to disasters (UNESCAP and UNISDR 2012). Because the countries in the Asia-Pacific region are important players in the world economy, reducing the loss of human life and property is essential to accelerate and sustain regional and global growth. Natural disasters cannot be prevented completely, so reducing disaster risk is a cost-effective investment in mitigating future losses especially in the developing countries. With the advent of modern science and technology and the development of global supply chains, all the regions in the world are interlinked. The impact of a disaster on one region is felt in other regions as well. It is important that various stakeholders across the world are brought to a common platform to share information, analyze data, and plan for future courses of action that reduce disaster risks. The United Nations International Strategy for Disaster Reduction (UNISDR) provides one such platform through its world conferences on disaster risk reduction (DRR). These meetings 
bring in governments, academia, private sector entities, nongovernmental organizations (NGOs), and communities together in pursuit of a common goal.

The three world conferences in Yokohama 1994, Hyogo 2005, and recently in Sendai 2015 have played a crucial role in the evolution of disaster management from a reactive to a proactive approach. The themes of the conferences have changed from "prevention, preparedness and mitigation" to "disaster reduction," and more recently to "disaster risk reduction" with a vision to safeguard human life, reduce economic loss, and contribute to sustainable development. The outcomes of each conference are the formulation and implementation of polices and measures that are supported by awareness generation, risk assessments, early warning systems, and emergency response capacities (Briceño 2015). The World Conference on Disaster Risk Reduction (WCDRR) in Sendai was held to facilitate the development of a post-2015 framework for DRR with a vision to develop a concise, focused, forwardlooking, and action-oriented outcome document. To support this objective, various regional meetings were held before the WCDRR to provide input for the outcome document of the Sendai conference. For the Asia region, the 6th Asian Ministerial Conference for Disaster Risk Reduction (AMCDRR), which was held in 2014 in Bangkok, Thailand, became a forum to generate recommendations for the WCDRR in Sendai.

This article is a quick response to the results of the WCDRR held in March 2015 in Sendai and AMCDRR held in Bangkok in 2014. We concentrate on the final outcome of series of discussions involving four types of stakeholders: local authorities; children and youth; science and technology; and private sector representatives. The authors participated in the WCDRR and draw heavily upon negotiations and discussions that occurred during the conference and from the summary documents of WCDRR, AMCDRR, and other relevant conferences. Section 2 sets the context for and importance of the selected stakeholders in the Asian setting. The following two sections detail the commitments made by the stakeholders in AMCDRR and WCDRR. Section 5 discusses the synergies and gaps that impact creation of a road map for the AMCDRR, which will take place in India in 2016. Section 6 presents several recommendations for the AMCDRR in 2016.

\section{Thematic Areas and Their Importance in Asia}

The article considers four thematic areas (local authorities, science and technology, children and youth, and business and industry) that are crucial for Asian development. This section provides insight into the relevance of each of the groups in their Asian context.
In Asia, local authorities provide various services to their communities and act as the implementing agency for most of the DRR work. All levels of local authorities across Asia have varying capacities. In general, the local authorities play an important role in local development planning, promote comprehensive school safety, encourage disaster resilient cities and villages through community-based DRR at the local level, and promote development of communitybased support networks (Tozier de la Poterie and Baudoin 2015). The Hyogo Framework for Action 2005-2015 (HFA) called for the strengthening of local authorities for DRR. How the third WCDRR and the Sendai Framework for Disaster Risk Reduction 2015-2030 (SFDRR) proposed to enhance the role and responsibility of local communities in DRR is a key indicator of the progress to expect in the next decade and a half.

More than half of the world's young people (representing both Children ${ }^{1}$ and Youth $^{2}$ ) between the ages of 10 and 24 are living in the Asia and the Pacific region, which is estimated to be around 650 million at present and is projected to increase to 700 million by 2030 (UNESCAP 2013). In recent disasters, for example Typhoon Haiyan 2013, Uttarakhand floods 2013, and Nepal earthquake 2015 , the education system particularly school structures have been badly affected. Youth and children have the capacity to innovate, educate, and reach out to the community and support training and awareness, which in turn could reduce the risk of future disasters. At the same time in Asian countries, due to lack of structured and institutionalized opportunities, the role of youth in the decisionmaking processes is limited.

Asia needs policies that seek to strengthen educational infrastructure, the institutions that carry out research and development (R\&D), and the innovation that is the need of the hour. Science and technology would necessarily cover education and advanced training, science and engineering (S\&E) workforce and mobility, R\&D expenditures and foreign direct investment, scientific publications, collaboration, and citations, patents, high-technology manufacturing and exports, services and trade in technical knowhow. All of these are essential for DRR in the Asian context, as between 1975 and 2011, $75 \%$ of the disaster deaths happened in Asia (UNESCAP and UNISDR 2012). Scientific data and information, and their linkages with policies and decision making across the public, private, and voluntary sectors, are needed to reduce the risk of disasters in Asia.

\footnotetext{
${ }^{1}$ The United Nations Convention on the Rights of the Child defines child as "a human being below the age of 18 years."

2 The United Nations, for statistical purposes, defines "youth" as those persons between the ages of 15 and 24 years, without prejudice to other definitions by Member States.
} 
The majority of the economic losses incurred in recent Asian disasters has been borne by the private sector when in contrast to the public sector. Because Asia has emerged, as a global business hub with wide supply-chain networks, the impact of disasters is no longer restricted within the national boundaries. More than $70 \%$ of the capital investment is made by the private sector globally and in Asian economies, so it is important to secure these investments, which would reflect adversely on regional, national, and local economies if significant losses were to occur due to natural disasters. A future increase in the privatization of basic services and critical infrastructure is often predicted, which puts the onus on the private sector group to engage actively in DRR in Asia (Johnson and Shleifer 2004).

\section{Disaster Risk Reduction in Asia}

The Asian Ministerial Conference on Disaster Risk Reduction has been held since 2005 as a biennial conference in the Asia region to ensure political and stakeholder commitment to DRR implementation. This section discusses the outcome of the 2014 AMCDRR, and focuses on the commitment made by the four types of stakeholders considered in this article.

\subsection{Commitments in AMCDRR for Local Authorities}

The Bangkok Declaration on Disaster Risk Reduction in Asia and the Pacific 2014 (AMCDRR 2014a) reflects deliberations at the 6th AMCDRR, and calls on all governments and stakeholders to: (1) enhance resilience at local levels; (2) improve public investments for disaster and climate risk management; (3) strengthen public and private partnership for DRR; (4) promote the use and further development of science, technology, and innovation; (5) enhance governance, transparency, and accountability; (6) contribute to the post-2015 framework; and (7) build coherence between the post-2015 framework and the concurrent processes. The Statement of Voluntary Commitments of Mayor and Local Governments generated in the 6th AMCDRR (2014c) expects cities and local governments to play a much bigger role in the post-2015 framework. The major actions for the evolving post-2015 framework mentioned in the statement include: (1) strengthen the role and functions of local governments in DRR; (2) promote peer-to-peer learning amongst cities and local governments to enhance local resilience; and (3) design evacuation shelters and identify prospective evacuation sites. The statement also suggested the need to develop short-term and long-term DRR strategies.
Activities in the short-term strategies are mainly conducted at the local and national levels (AMCDRR 2014a). The major activities are: (1) involve local government in the formulation of risk assessment and technical guidelines; (2) improve regulations and local government' structure in DRR; (3) incorporate risk sensitivity into spatial and local planning, and (4) develop structures through which youth can participate in DRR programs.

\subsection{Commitments in AMCDRR in Children and Youth}

The Bangkok Declaration (AMCDRR 2014a) adopted at the 6th AMCDRR called upon governments to support for further inclusion of vulnerable groups in DRR, such as children and youth, with the aim of enhancing local resilience. Children and youth are recognized as not only a vulnerable group in disasters, but also as one of the stakeholders who can contribute to DRR. In fact, various stakeholders recognized the importance of inclusion of children and youth when five voluntary commitments out of 10 , annexed to the declaration, included the word "youth." For example, the stakeholder groups of Civil Society Organizations (AMCDRR 2014e) and Local Governments (AMCDRR 2014c) promised to promote youth participation in planning and implementation of DRR-related activities to build capacity at the local level. The main stakeholder group of Children, Youth and ChildCentered Organizations, which was composed of various child-centered humanitarian NGOs and United Nations organizations, expressed concern about children and youth due to their vulnerability in disasters and climate change in terms of health, education, and psychology. More than $50 \%$ of the world's youth between the age of 15 and 24 reside in the Asia-Pacific region, this stakeholder group issued a powerful call for the SFDRR to include the protection of children and youth as a central feature of the Sendai Framework. Children-centered stakeholders emphasized sanitation, education, and the safety of school buildings as essential to DRR rather than merely improving the participation of children and youth in DRR (AMCDRR 2014d). These groups made a commitment to take action to: (1) expand programs for children- and youth-centered DRR and climate change adaption (CCA); (2) disseminate research and advocate for the inclusion and participation of children and youth in DRR; (3) create a space for discussion and sharing of practices for school safety; and (4) coordinate and promote the Comprehensive School Safety (CSS) framework. The CSS framework rests on three pillars-safe learning facilities; school disaster management; and risk reduction and resilience education (UNISDR 2014). 


\subsection{Commitments in AMCDRR in Science and Technology}

The Bangkok Declaration (AMCDRR 2014a) also called for further development of science, technology, and innovation in the region through investment in research and higher education. Private sector enterprises, especially insurance agencies, were identified as potential stakeholders that can put scientific research forward by sound investment. The Bangkok Declaration envisaged affordable technology to be accessible and available to national and local governments, although local communities needed to facilitate technology transfer. In order to promote better understanding of risk, including the emerging risks from climate change, the declaration recommended case-based learning, sharing of comparable data on disaster losses, hazards, and vulnerabilities, and dissemination of the best practices among universities and scientific forums. The focus of this conference is the voluntary commitments made by the "Technology and Academic Stakeholder Group." The major commitments include: (1) improve collaboration with related stakeholders; (2) promote a holistic, science-based approach towards community resilience including physical, natural, and human aspects; (3) support the use of development in the field of science and technology through increased earth observation; (4) develop course curriculum and promote higher education in DRR; and (5) promote community- and problembased action research. Commitments made by the group encompassed a few time-bound targets such as at least five countries in the Asia-Pacific region will have two universities providing Masters level disaster education by 2016 . Similarly, financial commitments were made by the AXA Research Fund to grant risk research worth $€ 100$ million from 2013 to 2018. Medium-term targets, such as an increase in the number of national science foundations by $15 \%$ and expansion of monitoring and observation platforms by $10 \%$, were also affirmed as feasible by 2020 . Long-term targets, to be achieved by 2025 , include higher penetration and efficiency of weather forecasting and climate predictions, half of the country population to be brought under basic early warning systems for natural hazards, and enhanced performance (by $25 \%$ ) by the science ministries in science-based DRR activities.

\subsection{Commitments in AMCDRR 2014 for Private Sector}

In Asia, the private sector has faced more loss when compared to the public sector in the last decade. This differential loss potential let the AMCDRR to encourage more active participation of the private sector in DRR. The 5th AMCDRR in 2012 focused on the private sector's engagement by developing and supporting local and national governments' risk assessment as well as by increased resilience of building and investment decisions. Regarded as equally important were cooperation with multiple partners to prioritize resilience in land-use planning and design and promotion of investments resilient to the anticipated impacts of extreme climactic events and the new risks (water crisis, epidemics, urban flooding) arising from rapid urbanization (Perwaiz 2014). In the 6th AMCDRR, UNISDR formed the disaster risk reduction private sector partnership (DRR-PSP) with 13 Asian businesses houses and the Private Sector Advisory Group (PSAG) with four Asian members who have signed the Statement of Commitment for Disaster Prevention, Resilience and Risk Reduction (AMCDRR 2014b). Three action points with specific indicators as given in Table 1 were agreed to monitor the progress made in DRR in Asia.

(1) Action point-1 Improve collaboration of the private sector in DRR through improved engagement and greater partnership between the public and private, and private and nongovernment sectors, and also through increased collaboration within the private sector;

(2) Action point-2 Increase knowledge and capacity in resilient business practices among the private sector, with a focus on improving the resilience of the global supply chain starting at the grassroots level; and

(3) Action point-3 Promote standards and reporting for resilience.

\section{Developments in the Third WCDRR in Sendai 2015}

The 6th AMCDRR provided a unique opportunity for Asian DRR stakeholders to contribute and shape the SFDRR discussed during the WCDRR in Sendai. This section details the various discussions and outcomes with a focus on the major groups (local authorities, children and youth, science and technology, and business and industry), which resulted in the preparation of the SFDRR.

\subsection{Local Authorities as Key Actor for Local DRR}

Local governments need to play significant roles in local DRR. UNISDR developed the Local Government SelfAssessment Tool (LGSAT) under the initiative "Making Cities Resilient: My City is Getting Ready," with an intention to help cities and local actors to set baselines, identify, gaps, and have comparable data across local governments (UNISDR 2013). 
Table 1 Indicators and targets for private sector as decided in AMCDRR 2014

\begin{tabular}{|c|c|c|c|}
\hline Targets & Action point-1 & Action point- 2 & Action point- 3 \\
\hline $\begin{array}{l}\text { Short-term } \\
\text { (by WCDRR 2015) }\end{array}$ & & & $\begin{array}{l}\text { Industry-specific certification programs } \\
\text { developed and launched }\end{array}$ \\
\hline $\begin{array}{l}\text { Medium-term (by } \\
\text { AMCDRR 2016) }\end{array}$ & $\begin{array}{l}\text { Increase of private sector } \\
\text { partnership numbers in Asia by } \\
20 \% \\
\text { Increased involvement of private } \\
\text { sector in DRR at both the } \\
\text { national and international levels } \\
\text { Guidance and examples of how } \\
\text { the private sector can } \\
\text { collaborate with governments/ } \\
\text { NGOs to build resilience } \\
\text { Two examples of risk } \\
\text { information sharing }\end{array}$ & $\begin{array}{l}\text { Small and medium enterprise (SME) } \\
\text { Business Continuity Management } \\
\text { (BCM)/Business Continuity Planning } \\
\text { (BCP) case studies, describing resilient } \\
\text { business practices } \\
\text { Method to monitor business failure due } \\
\text { to disasters developed }\end{array}$ & $\begin{array}{l}\text { A baseline study towards promoting } \\
\text { standards and reporting }\end{array}$ \\
\hline $\begin{array}{l}\text { Long-term } \\
\qquad(3-5 \text { years })\end{array}$ & $\begin{array}{l}\text { Qualitative improvement of } \\
\text { collaboration } \\
\text { Increased engagement of private } \\
\text { sector partners with } \\
\text { government, civil society } \\
\text { organizations (CSOs) and } \\
\text { academia }\end{array}$ & $\begin{array}{l}\text { Local governments approached to assist } \\
\text { in reaching SMEs with BCM/BCP } \\
\text { Partnerships and mentorships between } \\
\text { large- and-small businesses } \\
\text { Practical and actionable toolkits } \\
\text { developed or adapted for Asian SMEs }\end{array}$ & $\begin{array}{l}\text { Increase in number of companies } \\
\text { referring to DRR in } \\
\text { annual/sustainability/corporate social } \\
\text { responsibility (CSR)/any other } \\
\text { business reports }\end{array}$ \\
\hline
\end{tabular}

Source AMCDRR (2014b)

The SFDRR proposed four priorities for action: (1) understanding disaster risk; (2) strengthening disaster risk governance to manage disaster risk; (3) investing in DRR for resilience; and (4) enhancing disaster preparedness for effective response, and to "Build Back Better" in recovery, rehabilitation, and reconstruction. Each priority for action has key activities at national and local levels. The SFDRR requests all stakeholders to take into consideration these key activities. The key activities in understanding disaster risk are expecting the local government to facilitate a science-policy interface for effective decision making in disaster risk management and to share disaster risk information with people. To achieve these goals, it is crucial to build the knowledge of government officials through sharing experiences, lessons learned, good practices, and training and education on DRR (Weichselgartner and Pigeon 2015). Further development of local frameworks of laws, regulations, and public policies is considered as one of the significant points for strengthening disaster risk governance and reducing disaster risk. Adopting and implementing local DRR strategies and plans are expected to be among the responsibilities of local government. The objective is to prevent the creation of risk, reduce existing risk, and strengthen the resilience of economy, society, health, and environment. Public and private investment is essential to enhance the economic status, social well-being, health security, and cultural resilience of individuals and communities. To accelerate investment in DRR for resilience, the allocation of necessary resources, including finance, is important for the development and the implementation of DRR strategies, policies, plans, laws, and regulations. In the key activities for this priority, the term "public and private partnership" is not shown in SFDRR, although such partnerships are emphasized in the commitment found in AMCDRR (AMCDRR 2014a). To enhance disaster preparedness for effective response and to "Build Back Better" in recovery, rehabilitation, and reconstruction phases, one of the challenges is to empower women and persons with disabilities. There is a need to promote gender equality and to make available universally accessible access to response, recovery, rehabilitation, and reconstruction resources. Establishing community centers, adopting gender and disability neutral public policies and actions, promoting cooperation among diverse institutions, multiple authorities, and related stakeholders, and other key activities will help to improve the status and condition of women and persons with disabilities. The term "Build Back Better," set against the extreme needs created by the Indian Ocean tsunami of 2004 has created practical implementation challenges due to differences in understanding and raising expectations, which were not matched by the reconstruction process on the ground (Kennedy et al. 2009). 
The SFDRR identified national and local governments as important stakeholders who need to engage fully or partially with other stakeholders such as civil society and volunteers, research institutions, private sector enterprises, and the media for strengthening resilience.

\subsection{Children and Youth as Agents of Change}

Agenda 21 of the UN Conference on Environment and Development in Rio in 1992 described children and youth as one of the necessary nonstate stakeholders to achieve sustainable development and formed the basis for the selection of major groups in the third UN WCDRR. But children and youth have long been considered as particularly vulnerable groups, though they have a great deal to contribute to DRR efforts (Cumiskey et al. 2015). Children and youth also were considered as passive victims and were hardly considered as contributors in DRR (Anderson 2005).

The SFDRR has been set up to guide "the substantial reduction of disaster risk and losses" (UNISDR 2015, p. 6) and it is necessary to include various stakeholders to accomplish this goal. The SFDRR acknowledges that children and youth are "agents of change" and calls for countries to make space and opportunity for children and youth to contribute to DRR through legislation, national practice, and educational curricula (UNISDR 2015, p. 20). Even though the SFDRR did not mention any particular role of children and youth, case studies demonstrate that they are capable of effective contributions to before, during, and after disaster phases (Cumiskey et al. 2015). Major groups, such as women and farmers (Stough and Kang 2015), have particular roles and responsibilities for policy decisions about and early warning of extreme events, but no such roles have been discussed in the SFDRR for children and youth. For example, SFDRR indicates that women's participation is essential to implement gendersensitive policies and indigenous people can contribute to early warning through their experiences and knowledge (UNISDR 2015). Children and youth have been found to share information of disaster preparedness with their community (Ronan et al. 2008), have brought creative and resourceful ideas to DRR activities (Bartlett 2008), and have engaged actively as volunteers in relief and response work (Perren-Klingler 1996).

In fact, The UN Major Group for Children and Youth (MGCY) sponsored a preliminary WCDRR forum whose web site (https://www.childrenyouth.org/involved) indicates that a large number of children and youth have been involved in DRR activities across various regions $(\mathrm{Cu}-$ miskey et al. 2015). According to data provided by the executive committee of the forum, approximately 1050 children and youth globally applied for the forum, of which 801 were from Asia and 199 from Africa. The children subgroup (below 15 years) was inadequately represented as part of MGCY in WCDRR with only four applicants in comparison to 727 applicants representing the youth subgroup. After screening, around 200 children and youth from 35 countries qualified and attended the forum, which did not include NGOs who work with children.

The SFDRR called on governments to involve children and youth in DRR programs with nonstate stakeholders. "Civil Society Organizations" and "Local Governments" made voluntary commitments at the 6th AMCDRR (AMCDRR 2014c, e), which admitted the importance of working with children and youth to strengthen local capacities. This is an important step considering the view of Fernandez and Shaw (2013) for making full use of knowledge and skills of children and youth. It is important to ensure a supporting environment by adults. In addition, the effectiveness of children and youth in sharing preparedness information can be enhanced through working with the scientific community and nonstate stakeholders.

\subsection{Science and Technology as a Key Actor for Information Sharing and Warning Systems}

The importance of science and technology in better understanding and coping with disasters has gained greater acceptance in recent years (Aitsi-Selmi et al. 2015). Soon after the adoption of the HFA, a collective consensus emerged that strategies for DRR require a more integrated approach that engages all scientists, engineers, and policy planners, and that policy guidelines in the post-HFA period should better integrate with science and technology. Over the previous years, several science-policy negotiations and multilateral dialogues contributed to the post-2015 framework for DRR, which identified the need to bring science and technology into the policy and planning mainstream for effective risk reduction.

One of the key recognition of the themes of the 2015 Tokyo conference was the emergence of science and technology stakeholder's group that collectively brought a number of recommendations such as prompting scientific DRR research; establishing a university and researcher network; sharing data and encouraging open sourcing; developing global standards for DRR. In line with this, the Tokyo Conference on International Study for Disaster Risk Reduction and Resilience in January 2015 was the culmination of several important preliminary events. Jointly organized by the Science Council of Japan, the Integrated Research on Disaster Risk (IRDR) program, and UNISDR, the resulting Tokyo Statement (Science Council of Japan et al. 2015) summarizes the overall strategic goals for actions that mainstream science and technology in DRR. The main agenda of this conference was to develop collective platform for evidence based learning, sharing and 
archiving disaster data, and developing uniform methodology on data collection and economic analysis of disasters (Science Council of Japan et al. 2015).

From an Asian perspective, a holistic approach is needed to better integrate science and technology with DRR policies in the light of the high economic losses the region has suffered from disasters. Although the region has advanced significantly as observed in the Bangkok Declaration, integration of science and technology in DRR is at present broadly based. While the SFDRR is surely a reflection of what has been agreed so far in Bangkok (AMCDRR 2014a), it is imperative to look at the commonalities and differences of these two important frameworks to understand the degree to which science and technology have entered the mainstream of DRR.

The Bangkok Declaration and the SFDRR outline the common priorities, such as rigorous DRR research, collaborative platforms for DRR, investment in risk research, and promotion of dialogues between policy planners, decisionmakers, and scientific and the technological communities. The issues identified in SFDRR stress advanced and affordable early warning, involve the private sector in disaster research, and share nonstrategic data among the member countries; all of these concerns are in line with the Bangkok Declaration. Purely on technical grounds, the proposal for updating the UNISDR (2009) terminology on DRR is praiseworthy. The challenge of the SFDRR, however, is found in the need to establish baseline data, mainly soft quantitative data that is supported by background analysis of a particular situation or a region and to overcome the absence of qualitative and quantitative targets for achievements. A follow-up AMCDRR in India will probably encompass strategies for implementation of the WCDRRs' priorities of actions. This view was echoed in the suggestions made by various countries to include "substantial" at the beginning of relevant targets to reflect a stronger qualitative option, while other countries proposed quantitative targets at the national level and qualitative targets for global achievements. Baseline data are important for damage and loss assessment, and a longer time range of data is needed in order to reveal meaningful trends, and align with methodologies that measure progress. The commitments made by the science and technology stakeholder group in the third WCDRR lack robustness and, unfortunately, are not accompanied with measurable targets. In contrast, stakeholder commitments made in the 6th AMCDRR are timebound and target-based.

\subsection{Involvement of Business and Industry for Urban Resilience and Safe Investments}

The first two WCDRR, in Yokohama and Hyogo, did not consider the private sector as an important stakeholder in
DRR. The UNISDR summary report (UNISDR 2013) suggests that across the world, the private sector's engagement in DRR has been sporadic. The third WCDRR in Sendai makes a conscious effort to engage the active participation of the private sector through various local, national, and regional dialogues. Two of the seven global targets focus on reducing direct disaster-induced economic loss and diminishing disaster damage to critical infrastructure as well as disruption of basic services by 2030 . The UN business and industry major group has committed to work with governments on resilient and risk-sensitive financial investment and resilience-building rating systems that would build knowledge and share best practices among various stakeholders. The role of the private sector as identified in SFDRR under various priorities is listed below.

Priority 1 "Understanding disaster risk," builds the knowledge of the private sector, through sharing experiences, lessons learned, good practices, and training and education on DRR. At the global and regional level, the private sector needs to establish, disseminate, and share good practices. Priority 2 "Strengthening disaster risk governance to manage disaster risk" focuses on the role of the private sector in developing quality standards, certifications, and awards for disaster risk management. Priority 3 concentrates on "Investing in disaster risk reduction for resilience" through structural and non-structural measures. The private sector is called on to assign the necessary financial and logistical resources with which the development and the implementation of DRR, plans strategies, policies, and legal mechanisms can be fostered. The SFDRR emphasizes setting up mechanisms for disaster risk transfer and insurance, risk sharing and retention, financial protection, and disaster resilient investment. In addition, the SFDRR emphasize on integrating DRR into financial and fiscal instruments and stresses the increase of business resilience, protection of vulnerable livelihoods, and security of productive assets throughout global supply chains.

The conference also emphasized the role of the private sector in urban resilience because a major share of investment in cities is made by the private sector and highlighted the importance of public-private collaboration for financing, design, construction, and maintenance of infrastructure. These priority areas of action, although related broadly to priorities identified in the 6th AMCDRR (2014a), lack indicators and specific time lines for implementation. The voluntary nature of the commitments undertaken at the WCDRR is not supported by a legally binding agreement, which leaves implementation open ended for the private sector and other stakeholders to determine as they see fit. Although the framework covers 15 years, there is no intermediate monitoring mechanism built into the framework's priorities for action and thus no formal instrument for periodic review of progress. 


\section{Discussion}

The recently concluded WCDRR in Sendai made a roadmap for various activities to be taken up for DRR across the world. For the next 15 years the SFDRR will act as a base for the Sustainable Development Goals to be adopted in New York in September 2015 and influence climate change negotiations in December 2015 in Paris (Kelman 2015). The 7th AMCDRR scheduled for India in 2016 will monitor the achievements of the 6th AMCDRR and will endorse a regional implementation plan based on the SFDRR for Asia. Briceño (2015) suggests that there is a need to balance the pace of DRR implementation with the accelerating need for greater DRR in the face of emerging, complex disaster scenarios. He critiques current DRR policies and measures, which are focused on preparedness for coping natural disaster physical impacts rather than reduction of social and economic vulnerabilities. Because the targets set by the 6th AMCDRR and the third WCDRR are crucial for developing a DRR framework for Asia, there is an absence of baseline data for the targets to build upon in most cases. The WCDRR recognized the need to disaggregate baseline data and has urged academic communities, government institutions, and civil society organizations (CSOs) to work towards better data collection and analysis as well as more consistent policy application based on the new, improved, and more comprehensive data sets that result.

The qualitative nature of most of the targets in WCDRR is a contrast to the mix of qualitative and quantitative targets with defined indicators advocated in the 6th AMCDRR. The SFDRR has 15 years in which to showcase its achievement, but it is essential that phased targets and related indicators are developed to support the framework. Proper monitoring mechanisms would be useful in realizing SFDRR's voluntary targets. Tracking the risk of losses will be helpful in determining whether the risk reduction measures undertaken are effective and efficient, and provide the basis on which to recommend changes in the implementation strategies for better realization of SFDRR priorities.

Overlap exists in the voluntary commitments made under various thematic headings, which suggests a need for coordination among the various stakeholders. In order to accommodate various Asian stakeholders, including the national governments, under one umbrella, the role of regional organizations is crucial. SFDRR felt a need to include increased participation from regional organizations like the Association of Southeast Asian Nations (ASEAN), the Asia-Pacific Economic Cooperation (APEC), and the South Asian Association for Regional Cooperation (SAARC) in the Asia-Pacific region and similar organization in other continents. Active participation of these regional organizations would enhance the standardization, certification, and quality of response to disasters.

The preparatory conferences and side events are important from the perspective of sharing experiences and increasing opportunities for informal dialogue among the participants, which can feed into the main events of the conference. The 6th AMCDRR was successful in linking up the side events and the main event in such a way that the side events influenced the final outcome of the conference. This increased a sense of ownership among the various stakeholder groups in the commitments that were subsequently made.

The major groups discussed in the article need to cooperate closely with each other in order to achieve their targets. The conceptual diagram (Fig. 1) shows the interdependency between the major groups and their key areas of possible collaboration. For example, business and industry group would support local government in risk assessment and the government can support the private sector by strengthening services and infrastructure. Similarly, science and technology group can innovate new products for DRR, which can be supported by the business houses. Bringing all the stakeholders onto a single platform in AMCDRR gave them clarity and brought out the need to collaborate more actively with each other but in WCDRR only a handful of them were invited, as a result limiting multisectoral commitments.

In order to understand their disaster risk situation, strengthen disaster risk governance, and manage these risks, local authorities require more expertise and resources. Cities across Asia exist at varied economic levels and possess different institutional capacity with which to engage in disaster management. Hence it is imperative that

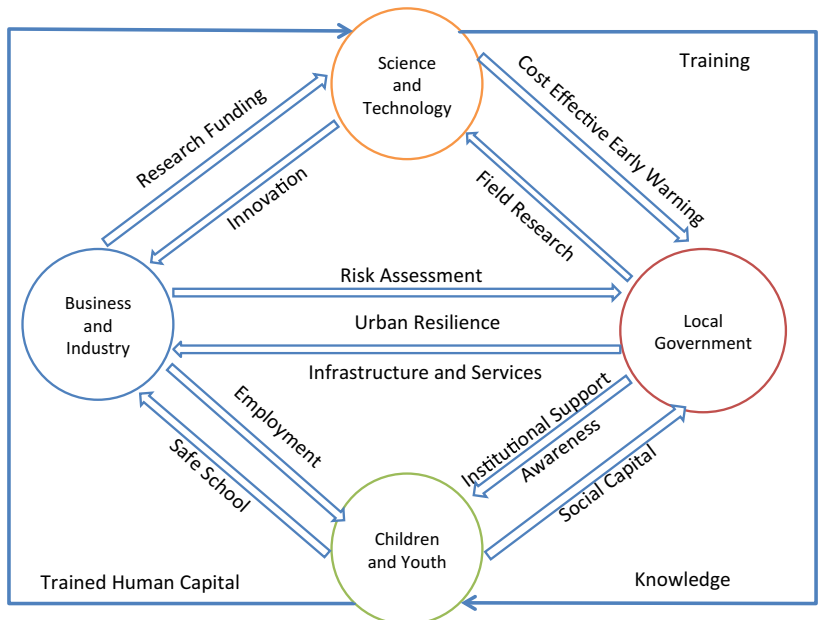

Fig. 1 Conceptual diagram showing symbiotic relation between the selected major groups 
an implementation plan is drawn up in the 7th AMCDRR to give due consideration to the various levels of cities in the urban hierarchy and their governance structure so customized implementation strategies can be created for each city through its national governments. Investing in DRR for resilience would require workable, deadlinespecific commitments and funds from the national governments and private sectors.

The private sector has grown in importance as a stakeholder in DRR after the 5th AMCDRR in 2012. In the Asian context, the private sector's resilience building will depend mainly on risk reduction for the small and medium scale enterprises (SMEs) that are the main contributors of the national GDP. Countries such as Thailand, where $99 \%$ or more of the total enterprises are SMEs, require a strong commitment to strengthen this group as was noted in the WCDRR. The 6th AMCDRR realized the need to focus on strengthening the role of SMEs in disaster management and the report of the United Nations Economic and Social Commission for Asia and the Pacific (UNESCAP 2015) likewise suggests strengthening SMEs for effective risk reduction. Regrettably, WCDRR 2015 had little representation from the SMEs and viable commitments for risk reduction were missing from the business houses, professional associations and private sector financial institutions, and the public sector for coordinated approach towards risk reduction. The business and industry major group did make oral commitments at the WCDRR plenary session in support of standardization and certification, the resilient cities initiative, and risk financing, but no clear action points exist to guide work toward specific goals. The challenge here is to translate commitments into action, as there are no targets or timelines for the commitments. Moreover, the SFDRR commitments are voluntary in nature and have no legal binding. They require good will and moral motivation to become reality.

In WCDRR, the private sector raised issues related to governance, trust, and missing regulatory frameworks as a hindrance to participation by the private sector. But the outcome of the conference relies heavily on the national governments to devise solutions to such problems. Paradoxically the achievements of the business and industry major group will now solely depend on the cooperation of the private stakeholders and national governments in regional platforms like AMCDRR. The role of regional organizations and regulatory bodies was underplayed in the SFDRR and there are no clear guidelines or commitments by which to involve these institutions in DRR activities.

The children and youth group are recognized as agents of change in the third WCDRR. But at the same time there is a need to disaggregate the children from the youth in order to address the vulnerabilities and capacities of these two distinct group and develop strategies for risk reduction activities. This is important because the absence of data limits information on specific age groups and hinders targeted policy planning and the allotment of resources across regions. The major challenge for the 7th AMCDRR will be to bring children and youth participation into risk assessments, disaster risk management planning, monitoring, and evaluation as well as active participation in national and local decision-making process.

\section{Recommendations}

The various points discussed in Sect. 5 suggest that between the three world conferences and other regional level conferences the disaster management sector has evolved considerably and has brought in focused approaches in order to streamline the various DRR initiatives. The recommendations suggested here are made in view of the approaching AMCDRR 2016 where an implementation plan of the SFDRR will be worked out for Asia:

(1) Create baseline data and quantitative indicators for monitoring the achievement of SFDRR.

As done in the 6th AMCDRR in Bangkok, the various priorities of actions suggested in the SFDRR need to have a baseline upon which the targets can be built. These baselines also can assist in periodic review of the achievements, strategies, and plans for enhancing the implementation process. National and local governments should play a leading role in collecting and collating the necessary data with the support of the academic institutions. Regional organizations including ASEAN, SAARC, and others, as well as international organizations, need to take an active part in setting up baselines for different regions and for Asia as a whole.

(2) Develop a common platform to discuss, share, and strategize with the various stakeholders.

The WCDRR provided a common platform to discuss the various concerns and share the commitments of each of the major groups, but the final statements were made mainly by the intergovernmental panel. As a result there was a disconnect between the various high level discussions, side events, and the final outcome of the conference. Analyzing the commitments, it is clear that a majority of them would need support from other stakeholders. But these stakeholders might not be aware of the roles and responsibilities that have devolved to them, since there was no meaningful exchange of views between the various $\mathrm{UN}$ major groups. An extensive discussion process is extremely difficult although not impossible at the global level. Yet at a regional level such a platform is 
both absolutely necessary and achievable as part of a logical working plan for the SFDRR in Asia.

(3) Prepare a city typology and classification to act as the base for local authorities' action plans.

The world is urbanizing at a rapid rate and so is Asia. As a result, urban resilience features prominently in the present DRR discourse. Looking at previous urban interventions, most of them were based on the premise that the resources and capacities of city governments are the same throughout the region. In reality, the situation varies from city to city and from one country to the other. It is necessary to design implementation plans that are customized to suit the needs of each city depending on its various hazards and risks, governance structure, and financial and institutional capacities.

(4) Disaggregate data on children from the data on youth. The disaggregation of data and development of different strategies are needed for both children and youth since each group has unique needs. It is a challenge to involve youth and children in the decision-making process in the same way that access to decision-making processes are difficult for the parents of the children and youth. The onus of involving the youth in the decision-making process lies on local governments, whose innovation and inclusiveness will be severely tested.

(5) Raise the awareness levels and capacity-building potential of students.

Raising the awareness level of children and youth through schools, universities, and national and local level campaigns is the need of the hour. Both groups should be made aware of local disaster risks and trained to respond in such emergencies. The school curriculum across Asia in highly disaster prone countries should include disaster management as a compulsory subject for junior high school students. For technical subjects that have direct links to disaster management professions like architecture and civil engineering, the curriculum should be modified to include specific topics at the undergraduate and postgraduate level.

(6) Enhance the private sector's role through involvement with regional organizations and regulatory bodies operating in collaborative partnerships.

Regional organizations like ASEAN and SAARC need to be actively engaged in bringing the private sector into DRR. These regional organizations can play an important role in increasing trans-border collaboration and may enhance the cooperation among national organizations for the private sector's involvement in humanitarian response (Chatterjee and Shaw 2015). Regional regulatory bodies like the Asia-Pacific
Chambers of Commerce and Industry (CACCI) and ASEAN Economic Community (AEC) should play an important role in the institutionalization of disaster management as well as bring in standardization and certification in disaster management.

(7) Encourage large enterprises to engage in partnerships with SMEs to build a culture of safety.

A majority of the enterprises in Asia are SMEs who have a considerable share in their country's GDP. It is important that DRR is internalized in SME businesses. During the WCDRR, the private sector was mainly represented by large enterprises. These largescale enterprises need to link up more closely with the SMEs who are local services providers for most of these large enterprises. A culture of safety is often an integral part of large corporations, and closer collaboration between different scale organizations can promote a trickle-down effect that diffuses safety to the other small-scale organizations. Enterprises with subsidiary offices across various countries should make necessary plans for managing disaster risk in accordance with the national guidelines.

(8) Share database information via networking.

Sharing of information among various stakeholders and among countries is important for timely disaster warnings and effective post-disaster response. Regional organizations with disaster management centers in different parts of Asia could play an important role in sharing risk information across various geographical regions. Sharing of satellite imagery in the public domain for disaster prone areas and post-disaster analysis will help not only the research community but also assist other stakeholders who are involved in response and relief.

\section{Conclusion}

The WCDRR in Sendai has brought in a new set of priorities for action to be implemented over the next 15 years across the world. As an outcome of this conference and preceding ones in the Asian context, it becomes clear that there is a need to bring all stakeholders onto a common discussion platform and support them all to achieve a better coordinated approach for DRR. In order to tackle the issues of rapid urbanization in Asia, it is important to enhance the role of local authorities and the private sector (mainly the SMEs) to safeguard critical infrastructure and make investments disaster resilient. Regional organizations need to have a greater role in the creation of risk information and must share data across the national governments. The implementation of the SFDRR working plan and its success will be based on how well each of the priorities for actions 
are represented and taken up for implementation in the future.

Acknowledgments The authors acknowledge the support from the Graduate School of Global Environmental Studies (GSGES) and Church World Service (CWS)-Asia Pacific for their participation in WCDRR in Sendai. The first and the third author thankfully acknowledge the Japanese Government (Monbukagakusho) Scholarship for conducting research in the GSGES in Kyoto University. The fourth author thankfully acknowledges the Global Survivability Studies (GSS) Scholarship for conducting research in the GSGES in Kyoto University.

Open Access This article is distributed under the terms of the Creative Commons Attribution 4.0 International License (http://creativecommons.org/licenses/by/4.0/), which permits unrestricted use, distribution, and reproduction in any medium, provided you give appropriate credit to the original author(s) and the source, provide a link to the Creative Commons license, and indicate if changes were made.

\section{References}

Aitsi-Selmi, A., K. Blanchard, D. Al-Khudhairy, W. Ammann, P. Basabe, D. Johnston, L. Ogallo, T. Onishi, et al. 2015. UNISDR STAG 2015 Report: Science is used for disaster risk reduction. http://preventionweb.net/go/42848. Accessed 3 Apr 2015.

AMCDRR (Asian Ministerial Conference on Disaster Risk Reduction). 2014a. Bangkok declaration on disaster risk reduction in Asia and the Pacific 2014. http://6thamcdrrthailand.net/6thamcdrr/Portals/ 0/Final\%20Bangkok\%20Declaration\%20-6\%20AMCDRR\%20final\%2026\%20June-0800\%20hours.pdf. Accessed 3 Apr 2015.

AMCDRR (Asian Ministerial Conference on Disaster Risk Reduction). 2014b. Bangkok declaration annex IX. Statement of voluntary commitments for disaster risk reduction-Private sector partnership-Asia for the 6th Asian Ministerial Conference for Disaster Risk Reduction. http://6thamcdrr-thailand.net/ 6thamcdrr/Portals/0/Annex\%2009\%20-\%20Private\%20Sector\% 20Statement $\% 20$ of $\% 20$ Voluntary\%20Commitments\%20FINAL $\%$ 2026\%20June\%202014.pdf. Accessed 3 Apr 2015.

AMCDRR (Asian Ministerial Conference on Disaster Risk Reduction). 2014c. Bangkok declaration annex V. Statement of voluntary commitments of mayors and local governments for the 6th Asian Ministerial Conference for Disaster Risk Reduction. http:// 6thamcdrr-thailand.net/6thamcdrr/Portals/0/Annex\%2005\%20-\% 20Mayors\%20and\%20Local\%20Governments\%20\%20FINAL\% 2026\%20June\%202014.pdf. Accessed 1 Apr 2015.

AMCDRR (Asian Ministerial Conference on Disaster Risk Reduction). 2014d. Bangkok declaration annex I. Statement of voluntary commitments of children, youth and child-centered organizations stakeholder group for the 6th Asian Ministerial Conference for Disaster Risk Reduction. http://6thamedrr-thai land.net/6thamcdrr/Portals/0/Annex\%2001-\%20Children\%20and\% 20Youth\%20final\%2026\%20June\%202014.pdf. Accessed 1 Apr 2015.

AMCDRR (Asian Ministerial Conference on Disaster Risk Reduction). 2014e. Bangkok declaration annex II. Statement of voluntary commitments of civil society organizations for the 6th Asia Ministerial Conference for Disaster Risk Reduction. http://6thamcdrr-thailand.net/6thamcdrr/Portals/0/Annex\%2002Civil\%20Society\%20Organisation\%20Final\%2026\%20June\%202 014.pdf. Accessed 1 Apr 2015.

Anderson, W.A. 2005. Bringing children into focus on the social science disaster research agenda. International Journal of Mass Emergencies and Disasters 23(3): 159-175.
Bartlett, S. 2008. The implications of climate change for children in lowerincome countries. Children Youth and Environments 18(1): 71-98.

Briceño, S. 2015. Looking back and beyond Sendai: 25 years of international policy experience on disaster risk reduction. International Journal of Disaster Risk Science 6(1): 1-7.

Chatterjee, R., and R. Shaw. 2015. Role of regional organizations for enhancing private sector involvement in disaster risk reduction in developing Asia. In Disaster management and private sectors, ed. T. Izumi, and R. Shaw, 47-67. Tokyo: Springer Japan.

Cumiskey, L., T. Hoang, S. Suzuki, C. Pettigrew, and M.M. Herrgård. 2015. Youth participation at the Third UN World Conference on Disaster Risk Reduction. International Journal of Disaster Risk Science 6(2). doi: 10.1007/s13753-015-0054-5.

Fernandez, G., and R. Shaw. 2013. Youth Council participation in disaster risk reduction in Infanta and Makati, Philippines: A policy review. International Journal of Disaster Risk Science 4(3): 126-136.

Guha-Sapir, D., R. Below, and Ph. Hoyois. 2015. EM-DAT: International Disaster Database. Université Catholique de Louvain, Brussels, Belgium. http://www.emdat.be. Accessed 1 June 2015.

Johnson, S., and A. Shleifer. 2004. Privatization and corporate governance. Governance, regulation, and privatization in the Asia-Pacific region. NBER East Asia Seminar on Economics, vol. 12. http://www.nber.org/chapters/c10182. Accessed 1 June 2015.

Kelman, I. 2015. Climate change and the Sendai framework for disaster risk reduction. International Journal of Disaster Risk Science 6(2). doi:10.1007/s13753-015-0046-5.

Kennedy, J., J. Ashmore, E. Babister, I. Kelman, and J. Zarins. 2009. Disaster mitigation lessons from "build back better" following the 26 December 2004 Tsunamis. In Water and urban development paradigms, ed. J. Feyen, K. Shannon, and M. Neville, 297-302. London: Taylor \& Francis Group.

Perren-Klingler, G. 1996. Human reactions to traumatic experience: From pathogenetic to salutogenic thinking. In Trauma: From individual helplessness to group resources, ed. G. PerrenKlingler, 7-28. Berne: Paul Haupt Publishers.

Perwaiz, A. 2014. The next chapter on business: Resilient investment to protect gains. Asian Disaster Management News, Special Edition. http://www.adpc.net/igo/category/ID601/doc/2014imd5Ht-ADPC-ADPC_Newsletter_Special_Edition_2014_Web. pdf. Accessed 3 Apr 2015.

Ronan, K.R., K. Crellin, D.M. Johnston, K. Finnis, D. Paton, and J. Becker. 2008. Promoting child and family resilience to disasters: Effects, interventions, and prevention effectiveness. Children Youth and Environments 18(1): 332-353.

Science Council of Japan, UNISDR (United Nations International Strategy for Disaster Reduction), IRDR (Integrated Research on Disaster Risk), The Tokyo University. 2015. Tokyo statement. Towards a new science and technology to consolidate disaster risk reduction and sustainable development. http://monsoon.t. utokyo.ac.jp/AWCI/TokyoConf/en/pdf/Tokyo.Statement_ Action.Agenda.pdf. Accessed 15 Feb 2015.

Stough, L., and D. Kang. 2015. The Sendai framework for disaster risk reduction and persons with disabilities. International Journal of Disaster Risk Science 6(2). doi:10.1007/s13753-015-0051-8.

Tozier de la Poterie, A., and M.-A. Baudoin. 2015. From Yokohama to Sendai: Approaches to participation in international disaster risk reduction frameworks. International Journal of Disaster Risk Science 6(2). doi: 10.1007/s13753-015-0053-6.

UNESCAP (United Nations Economic and Social Commission for Asia and the Pacific). 2013. United Nations youth report. Regional overview: Youth in Asia and the Pacific. http://www. un.org/esa/socdev/documents/youth/fact-sheets/youth-regionalescap.pdf. Accessed 9 Apr 2015. 
UNESCAP (United Nations Economic and Social Commission for Asia and the Pacific). 2015. Overview of natural disasters and their impacts in Asia and the Pacific, 1970-2014. http://www. unescap.org/sites/default/files/Technical\%20paper-Overview\%20 of $\% 20$ natural $\% 20$ hazards $\% 20$ and $\% 20$ their\%20impacts_final.pdf. Accessed 9 Apr 2015.

UNESCAP (United Nations Economic and Social Commission for Asia and the Pacific) and UNISDR (United Nations International Strategy for Disaster Reduction). 2012. Reducing vulnerability and exposure to disasters: The Asia-Pacific disaster report 2012. http://www.unisdr.org/files/29288_apdr2012finallowres.pdf. Accessed 3 June 2015.

UNISDR (United Nations International Strategy for Disaster Reduction). 2009. Terminology. http://www.unisdr.org/we/inform/ter minology. Accessed 12 May 2015.

UNISDR (United Nations International Strategy for Disaster Reduction). 2013. The local government self-assessment tool (LGSAT). http://www.unisdr.org/campaign/resilientcities/toolkit/howto. Accessed 27 Mar 2015.

UNISDR (United Nations International Strategy for Disaster Reduction). 2014. Comprehensive school safety. http://www.preven tionweb.net/files/31059_31059comprehensiveschoolsafetyframe. pdf. Accessed 20 Mar 2015.

UNISDR (United Nations International Strategy for Disaster Reduction). 2015. Sendai framework for disaster risk reduction 2015 2030. http://www.wcdrr.org/uploads/Sendai_Framework_for_ Disaster_Risk_Reduction_2015-2030.pdf. Accessed 20 Mar 2015.

Weichselgartner, J., and P. Pigeon. 2015. The role of knowledge in disaster risk reduction. International Journal of Disaster Risk Science 6(2). doi:10.1007/s13753-015-0052-7. 